\title{
Hot-wire Laser Brazing Technology for Steel / Aluminum Alloy Dissimilar Joint*
}

\author{
by TAKAYA Shunsuke**, YAMAMOTO Motomichi***, SHINOZAKI Kenji***, MATSUDA Hiroshi**** \\ and IKEDA Rinsei****
}

\begin{abstract}
Hot-wire laser brazing was proposed for attaining a lap fillet dissimilar joint of galvanized (GI) steel sheet / A5052 sheet. Our results revealed that relatively sound brazing beads with/without a few defects were obtained at high brazing speeds of up to $4.0 \mathrm{~m} / \mathrm{min}$. Furthermore, the average thickness of the brittle intermetallic compounds formed at the joint interface was carefully controlled and ranged from $<1 \mu \mathrm{m}$ to several $\mu \mathrm{m}$. Moreover, a high tensile strength of the joint was realized; this strength is $80 \sim 90 \%$ of the base galvanized (GI) steel strength.
\end{abstract}

Key Words: Hot-wire, Laser brazing, Dissimilar joining, Steel / Aluminum alloy

\section{Introduction}

In response to global warming, the automobile industry has focused on reducing fuel consumption and, in turn, automobile emissions by light-weighting the automobile body. This must be achieved while maintaining workability, cost-efficiency, safety, and maneuverability of the automobile. Therefore, the use of aluminum alloys (rather than conventional steels) in the automobile body structure has received significant attention, and the demand for steel / aluminum alloy dissimilar joints has increased $^{1,2)}$.

Dissimilar joining for steel / aluminum alloy via conventional fusion welding methods leads to the formation of brittle intermetallic compounds (IMC) at the joint interface, thereby resulting in undesirable joint properties. Therefore, in the current automobile industry, steel / aluminum joints are achieved via mechanical joining and adhesion ${ }^{3,4)}$. Furthermore, from the viewpoint of improving productivity and joint properties by reducing IMC formation, various studies have focused on joint formation via brazing using laser, MIG or CMT methods ${ }^{1,3,5-8)}$. The processing speed of these methods is, however, inadequate for practical use, and leads to extremely thick (thickness: $>10$ $\mu \mathrm{m}) \mathrm{IMC}$ and, consequently, significant deterioration of the joint strength under some conditions. Hence, a novel joining method for the formation of steel / aluminum alloy dissimilar joints is essential.

The aim of this study is to investigate the applicability of hot-wire laser brazing to the formation of steel / aluminum alloy

\footnotetext{
${ }^{*}$ Received: 2016.10 .17

** Student Member, Graduate school of Engineering, Hiroshima University

dissimilar joints. A filler wire, with a tip electrically heated (via Joule heating) to temperatures near its melting point, is fed during this process. Moreover, a reduction in IMC formation is expected, owing to the low heat input and high brazing speed of the process. In this study, hot-wire laser brazing was performed on a lap fillet joint of steel sheet / aluminum alloy sheet. The high brazing speed processability, IMC formation, and joint strength were investigated via tensile shear tests.

\section{Materials and experimental procedures}

Galvanized (GI) steel sheets (270 MPa-class, thickness: 0.8 $\mathrm{mm}$ ) and A5052 aluminum alloy sheets (thickness: $1.2 \mathrm{~mm}$ ) were used as base metals. The chemical composition of each of these metals is shown in Table 1. An Al-12\%Si solid wire (JIS BA4047, diameter: $1.2 \mathrm{~mm}$ ) and a chloride-based powdered flux were used as a filler wire and for general aluminum alloy brazing, respectively. As shown in Fig. 1, 100(W) $\times 150(\mathrm{~L})$ specimens of the base metals were used, and the lap fillet joint was formed by placing the A5052 sheet on the GI steel sheet with a $10-\mathrm{mm}$ overlap. The flux was mixed with water (in a weight ratio of 2:1), which yielded a paste that was then applied to the brazing line of the base metals (see Fig. 1). Table 2 shows the brazing conditions and Fig. 2 shows the schematic illustration of the experimental set-up. A $6.0-\mathrm{kW}$ diode laser oscillator and hot-wire power supply were used during brazing. The optical lens creating a 4-mm-diameter laser spot at the just-focus position was used with a 30-mm defocus length. Ar shielding gas was blown from a hot-wire torch (co-axial) and both sides of a brazing bead. Lap fillet joints were formed at various values of brazing speed and laser power, for a fixed ratio (i.e., 1:5) of brazing speed to 
Table. 1 Chemical composition of each base material.

\begin{tabular}{|c|c|c|c|c|c|c|c|c|}
\hline \multirow{2}{*}{ Material } & $\begin{array}{c}\text { Quantity of } \\
\text { plating, } \mathrm{mg} / \mathrm{m}^{2}\end{array}$ & $\mathrm{C}$ & $\mathrm{Mn}$ & $\mathrm{Si}$ & $\mathrm{P}$ & $\mathrm{S}$ & $\mathrm{Fe}$ \\
\hline Gl steel sheet & $60 / 60$ & 0.001 & 0.09 & 0.007 & 0.007 & 0.008 & $\mathrm{Bal}$. \\
\hline \multirow{2}{*}{ Material } & \multicolumn{7}{|c|}{ Chemical compositions, mass \% } \\
\cline { 2 - 8 } & $\mathrm{Si}$ & $\mathrm{Fe}$ & $\mathrm{Cu}$ & $\mathrm{Mn}$ & $\mathrm{Mg}$ & $\mathrm{Cr}$ & $\mathrm{Zn}$ & $\mathrm{Al}$ \\
\hline A5052 sheet & 0.07 & 0.28 & 0.01 & 0.01 & 2.58 & 0.17 & 0.00 & Bal. \\
\hline
\end{tabular}

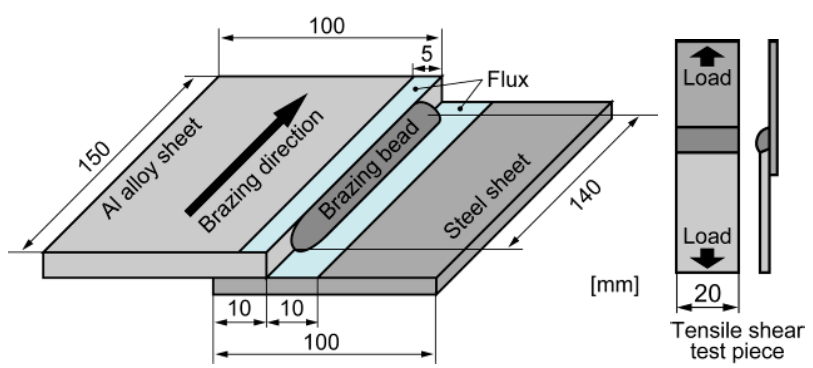

Fig. 1 Schematic illustration of the specimens.

Table. 2 Brazing conditions.

\begin{tabular}{|c|c|c|c|c|}
\hline \multicolumn{2}{|c|}{ LD laser power, $\mathrm{kW}$} & \multicolumn{3}{|c|}{$2.5 \sim 6.0$} \\
\hline \multicolumn{2}{|c|}{ LD focus spot size, $\mathrm{mm}$} & \multicolumn{3}{|c|}{$\phi 4$} \\
\hline \multicolumn{2}{|c|}{ Defocus length, $\mathrm{mm}$} & \multicolumn{3}{|c|}{30} \\
\hline \multicolumn{2}{|c|}{ Laser irradiation angle, deg } & \multicolumn{3}{|c|}{5} \\
\hline \multicolumn{2}{|c|}{ Laser irradiation position, $\mathrm{mm}$} & \multicolumn{3}{|c|}{0.5} \\
\hline \multicolumn{2}{|c|}{ Brazing speed, $\mathrm{m} / \mathrm{min}$} & 2.0 & 3.0 & 4.0 \\
\hline \multicolumn{2}{|c|}{ Wire feeding speed, $\mathrm{m} / \mathrm{min}$} & 10.0 & 15.0 & 20.0 \\
\hline \multicolumn{2}{|c|}{ Wire current, $\mathrm{A}$} & 185 & 220 & 240 \\
\hline \multicolumn{2}{|c|}{ Power supply distance, $\mathrm{mm}$} & \multicolumn{3}{|c|}{80} \\
\hline \multicolumn{2}{|c|}{ Wire feeding angle, deg } & \multicolumn{3}{|c|}{45} \\
\hline \multicolumn{2}{|c|}{ Wire feeding position, $\mathrm{mm}$} & \multicolumn{3}{|c|}{2} \\
\hline \multirow{2}{*}{$\begin{array}{c}\text { Ar shielding gas, } \\
\mathrm{L} / \mathrm{min}\end{array}$} & Coaxial & \multicolumn{3}{|c|}{20} \\
\hline & Each side & \multicolumn{3}{|c|}{15} \\
\hline
\end{tabular}

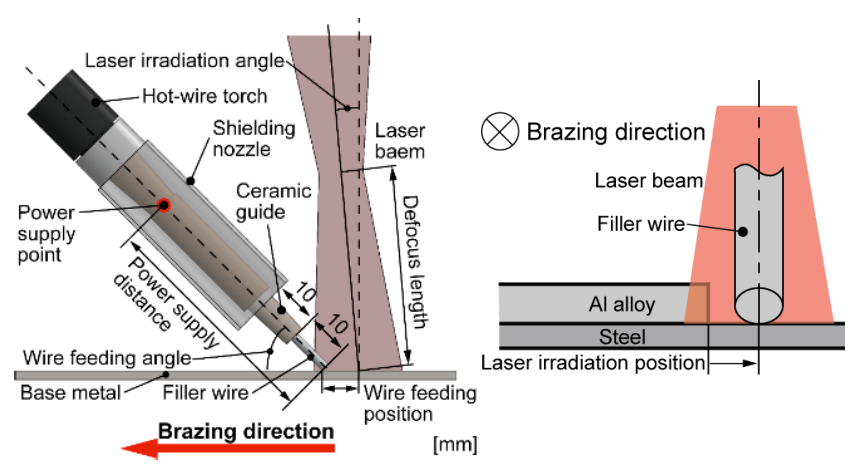

Fig. 2 Schematic illustration of the experimental set-up.

hot-wire feeding speed. A hot-wire, with sufficient current for Joule heating without melting of the filler wire tip, was fed from the front side in the brazing direction. The IMC formed at the joint interface was investigated by using a scanning electron microscope (SEM) equipped with an energy dispersive X-ray spectrometer (EDX) to examine the cross-section of each joint. In addition, the joint strength was evaluated by performing tensile shear tests on two strip-shaped specimens having a $20-\mathrm{mm}$ (width) cut off from each joint (see Fig. 1). The fractured specimens were also investigated via SEM-EDX.

\begin{tabular}{|c|c|l|}
\hline $\begin{array}{c}\text { Brazing } \\
\text { speed, } \\
\text { m/min }\end{array}$ & $\begin{array}{c}\text { Laser } \\
\text { power, } \\
\mathrm{kW}\end{array}$ & Appearances $\stackrel{\text { Brazing direction }}{\longleftarrow}$ \\
\hline 2.0 & 2.5 & Steel \\
\hline 2.0 & 3.5 & \\
\hline 4.0 & 6.0 & (S) \\
\hline
\end{tabular}

Fig. 3 Typical examples of brazing bead appearances.

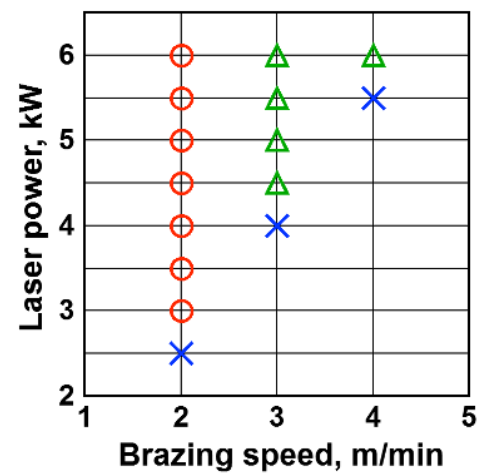

Fig. 4 Appearance evaluation of the brazing beads.

\section{Results and discussion}

\subsection{High speed processability of hot-wire laser brazing}

Figure 3 shows typical examples of brazing beads formed at the GI steel / A5052 lap fillet joints. As Fig. 3 shows, the bead appearance was classified into three types, namely: defect-free beads, beads with only a few pit-like defects, and beads with poor wetting or many defects. These beads are denoted by the $\circ, \Delta$, and $\times$ symbols, respectively. Figure 4 shows the relationship between the brazing speed and laser power associated with each of the bead appearances. For all brazing speeds and the lowest laser power, the brazing metal was insufficiently wetted to the steel side, thereby resulting in highly defective beads (denoted by $x$ in Fig. 4). Sound bead appearances (as indicated by $\circ$ and $\Delta$ in Fig. 4) were obtained at relatively high laser power and brazing speeds of $2.0-4.0 \mathrm{~m} / \mathrm{min}$.

\subsection{IMC formation at the joint interface}

Figure 5 shows typical SEM images and EDX line analysis results of IMC formed at the joint interface when a brazing speed of $2.0 \mathrm{~m} / \mathrm{min}$ and laser power of $3.0 \mathrm{~kW}$ are used. Layered and acicular-type IMC, which contain $\mathrm{Fe}, \mathrm{Al}$, and $\mathrm{Si}$, occur at the interface of all joints (see Fig. 5).

The distribution of layered IMC thickness was measured from the root to the toe along the bead width direction, as shown in Fig. 6. A brazing speed of $2.0 \mathrm{~m} / \mathrm{min}$, laser power of $6.0 \mathrm{~kW}$, and the 


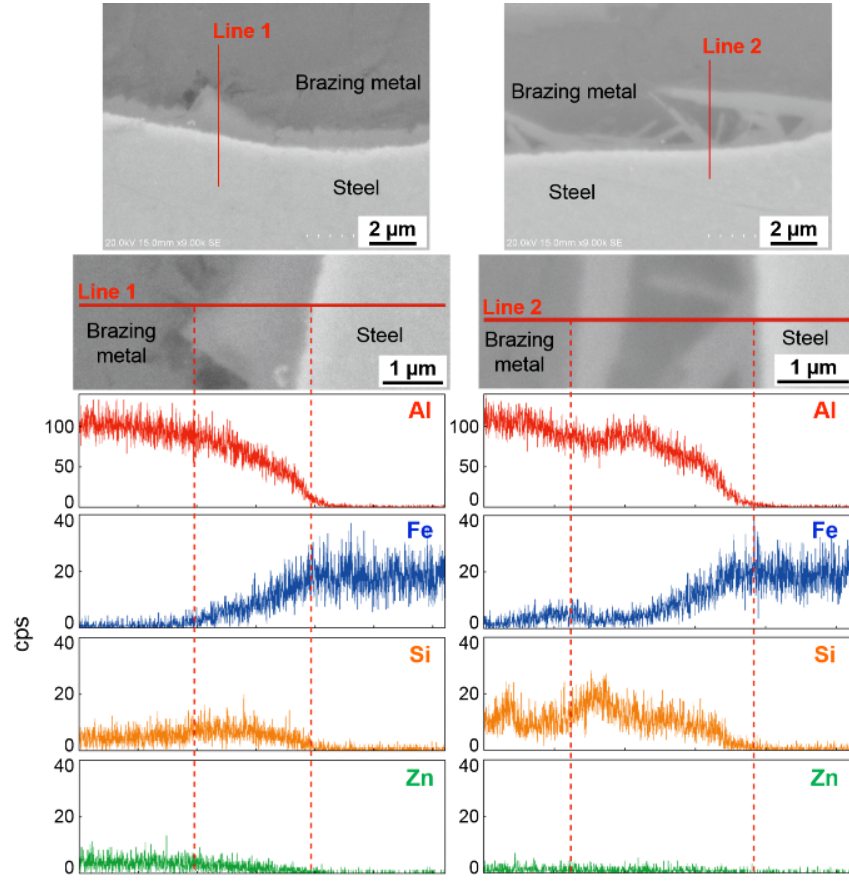

Fig. 5 Typical results of SEM-EDX investigation on IMC. (Brazing speed: $2.0 \mathrm{~m} / \mathrm{min}$, Laser power: $3.0 \mathrm{~kW}$ )

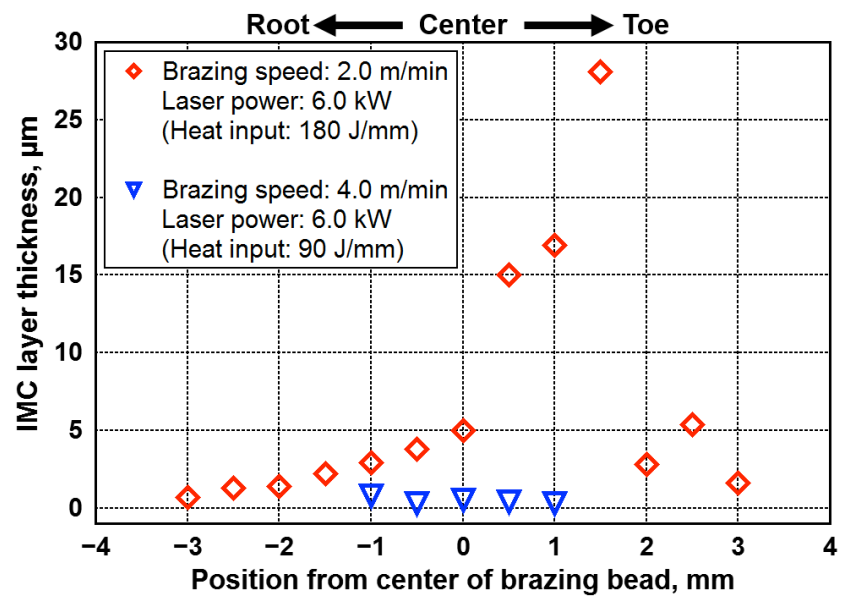

Fig. 6 Distribution of layered IMC thickness.

highest heat input, yield: relatively thick $(\sim 5-30 \mu \mathrm{m})$ IMC near the center of the bead and thin $(\sim 1-3 \mu \mathrm{m})$ IMC at the root and toe. However, a brazing speed of $4.0 \mathrm{~m} / \mathrm{min}$, laser power of $6.0 \mathrm{~kW}$, and lowest heat input yield IMC, from the root to the toe, that are all $<1 \mu \mathrm{m}$ thick.

\subsection{Joint strength and discussions}

Figure 7 shows typical load-deformation diagrams and types of fracture that occur during tensile shear tests of the joints denoted by $\circ$ or $\Delta$ in Fig. 4. The fracture was classified into three types, namely: type A: brazed metal fracture, type B: interfacial fracture between the steel sheet and the brazed metal, and type A+B: a combination of fracture types A and B. Although undergoing different types of fracture, all joints exhibit high fracture loads beyond the yielding point and the GI steel undergoes large plastic
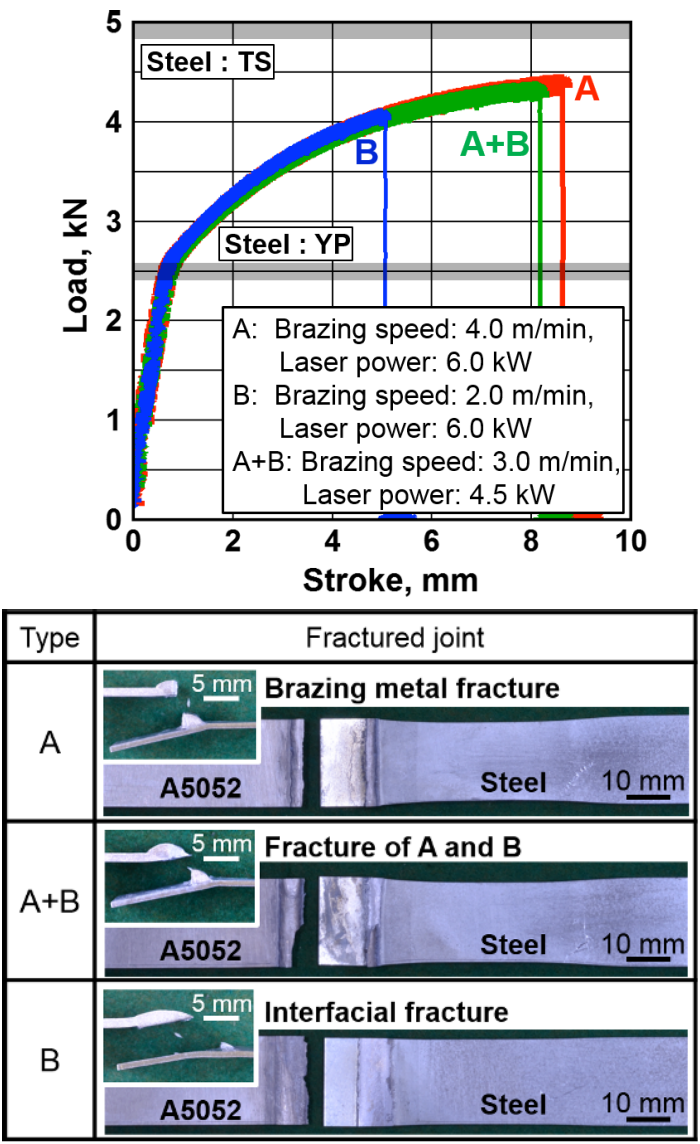

Fig. 7 Typical load-deformation diagrams and type of fracture occurring during tensile shear tests.

deformation.

The fracture surface of the specimen fractured at the joint interface was investigated via SEM-EDX, as shown in Fig. 8. Similar fracture surfaces occurred on both the steel side and the brazed metal side. A rugged fracture surface occurred at the root. The presence of $\mathrm{Al}$ and $\mathrm{Si}$ indicates that the fracture occurred in the brazed metal. A flat fracture surface occurs at the center along the bead width direction; the detection of $\mathrm{Al}, \mathrm{Si}$, and Fe indicates that fracture occurred in IMC at the joint interface.

In addition, the joint interface at the root near the fracture part was observed on the specimen fractured in the brazed metal shown in Fig. 9. IMC are not prominent near the fracture part in Fig. 9.

Based on these results, the fracture process occurring during tensile shear tests of the GI steel / A5052 lap fillet joint is schematically illustrated, as shown in Fig. 10. As the figure shows, a crack is initiated in the brazed metal at the root along the joint interface. This crack then propagates perpendicularly to the joint interface into the brazed metal, when the IMC is extremely thin and appear only vaguely at the root. However, when relatively thick IMC occur at the root, the crack propagates in IMC along the joint interface. In other words, the thickness of IMC in the root region has a significant effect on the fracture 


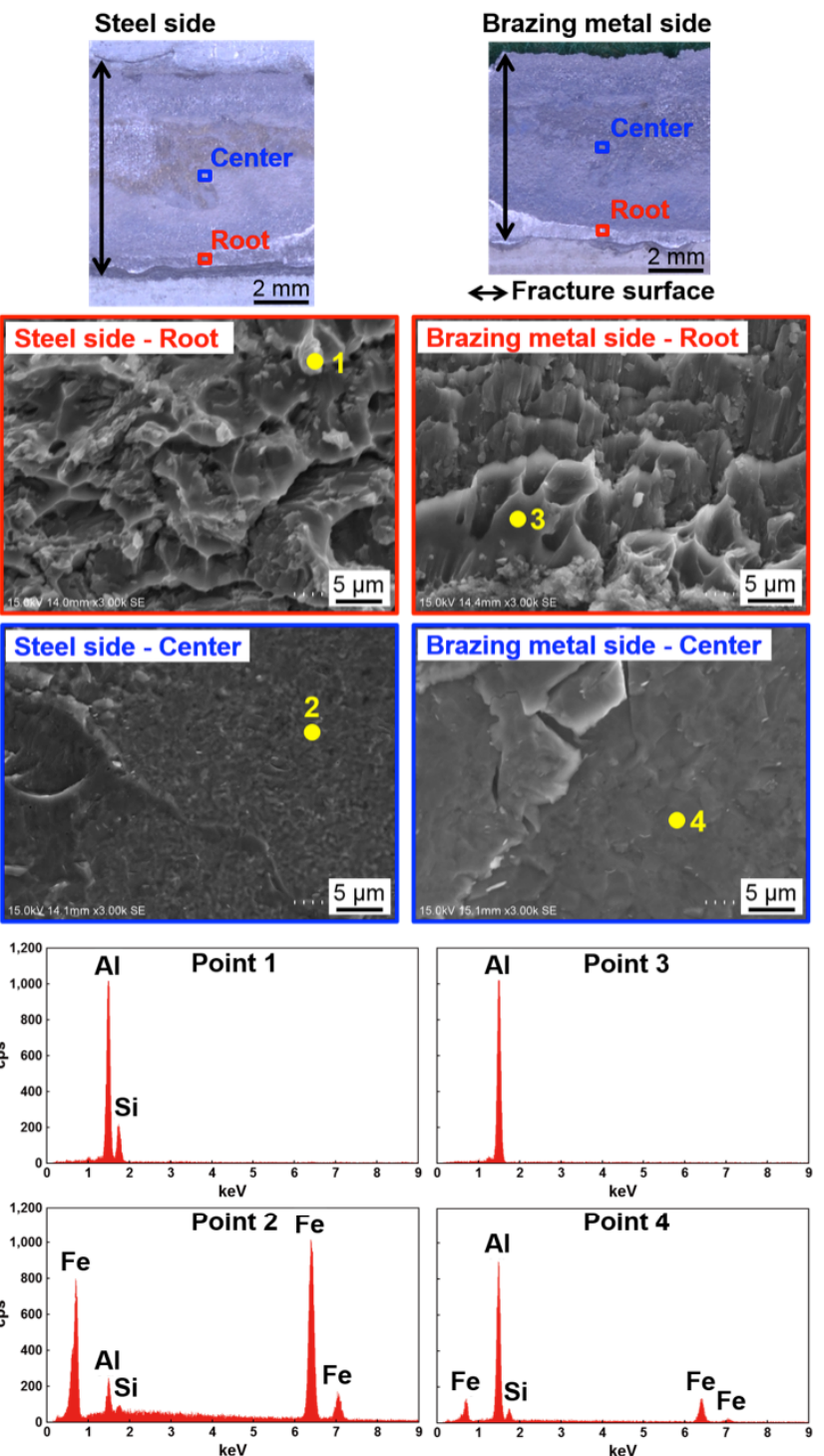

Fig. 8 SEM-EDX investigation on interfacial fracture surface.

(Brazing speed: $2.0 \mathrm{~m} / \mathrm{min}$, Laser power: $6.0 \mathrm{~kW}$ )

strength and pattern.

Figure 11 shows the dependence of the IMC layer thickness on the tensile shear strength and heat input. This thickness was classified into two types, namely: the thickness at the root and the average thickness from the root to the toe in the bead width direction. The heat input was calculated by dividing the laser power by the brazing speed. The average IMC thickness and IMC thickness at the root increase with increasing heat input (see Fig. 11 ), and approximate values of $7 \mu \mathrm{m}$ and $1 \mu \mathrm{m}$, respectively, are obtained. At the lowest heat input, these values decrease to (on average) $<1 \mu \mathrm{m}$ and $<0.5 \mu \mathrm{m}$, respectively. During the tensile shear tests, $80-90 \%$ of the tensile shear strength of the GI steel sheet strength can be achieved at all joints, independently of the heat input and average IMC thickness. The specimen fractured in the brazed metal without the occurrence of fracture along the steel / brazed metal joint interface subjected to the lowest heat input conditions; this interface is associated with joints where the IMC

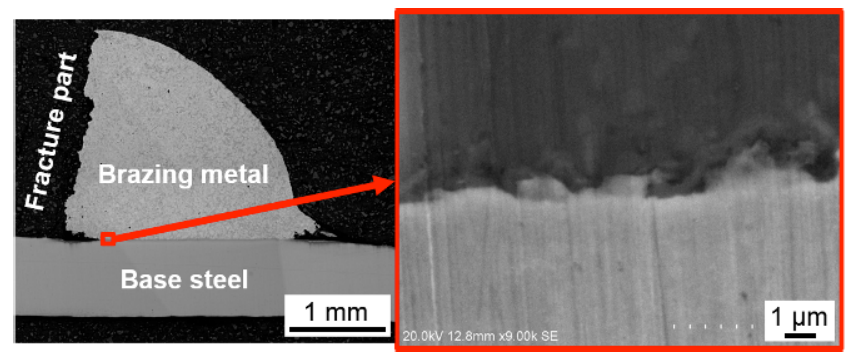

Fig. 9 Macrograph and SEM image near the fracture site of the specimen fractured in the brazed metal.

(Brazing speed: $4.0 \mathrm{~m} / \mathrm{min}$, Laser power: $6.0 \mathrm{~kW}$ )

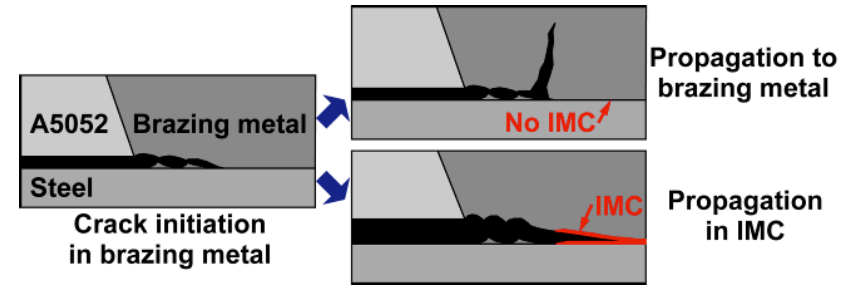

Fig. 10 Schematic illustration of fracture occurring during the tensile shear test.

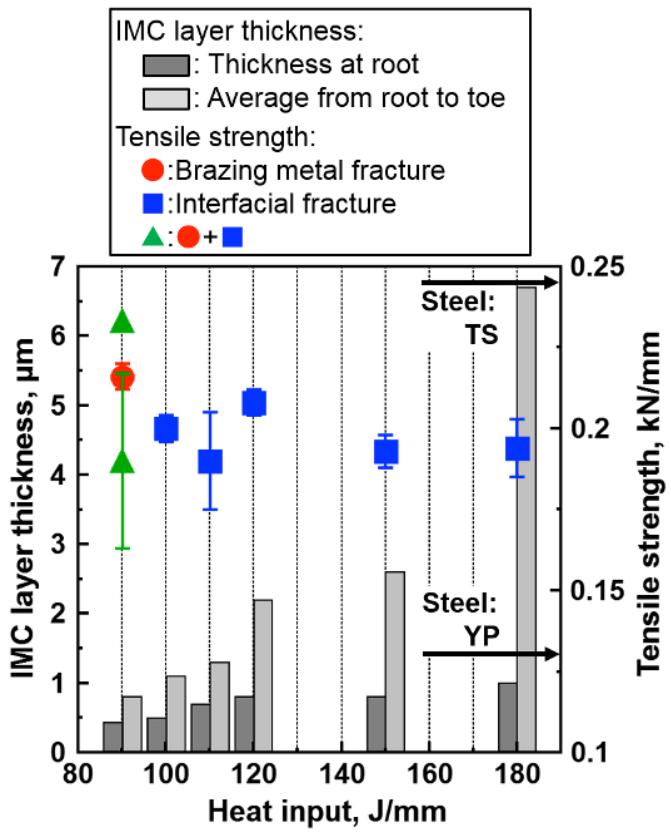

Fig. 11 Dependence of the IMC layer thickness and tensile strength on the heat input.

thickness is $<1 \mu \mathrm{m}$ (on average) and $<0.5 \mu \mathrm{m}$ at the root. Therefore, control of IMC formation, especially at the root, is essential for obtaining a sound GI steel / A5052 lap fillet joint with high fracture strength.

\section{Conclusions}

In this study, a hot-wire laser brazing technology was proposed for attaining a lap fillet joint of GI steel sheet / A5052 sheet. During this process, joints with relatively sound appearance with/without a few defects were obtained when sufficient laser power was applied at high brazing speeds of $2.0-4.0 \mathrm{~m} / \mathrm{min}$. The 
IMC layer thickness at the joint interface can be limited to values ranging from $<1 \mu \mathrm{m}$ to $7 \mu \mathrm{m}$ on average and $0.5 \mu \mathrm{m}$ to $1 \mu \mathrm{m}$ at the root, by applying appropriate conditions during the hot-wire laser brazing process. More importantly, the IMC thickness (especially at the root) has a significant effect on the joint strength and fracture process. A high tensile shear strength, which is $80-90 \%$ of the GI steel strength, can be obtained with sound bead appearance. Furthermore, the specimen with an IMC thickness of $<0.5 \mu \mathrm{m}$, at the root, fractured in the brazed metal without the occurrence of fracture along the joint interface.

\section{Reference}

1) S. Sasabe, T. Iwase, T. Matsumoto, Y. Hattori and T. Miono: Dissimilar Metal Joining of Aluminum Alloys to Steel in MIG Braze Welding by using the advanced Hot-dip Aluminized Steel Sheet, Journal of Japan Welding Society, 27-2 (2009), 55s-59s.

2) J. L. Song, S.B. Lin, C. L. Yang and C. L. Fan, Effects of Si additions on intermetallic compounds layer of aluminum-steel TIG welding-brazing joint: Journal of Alloys and Compounds, 488 (2009), 217-222.
3) H. Laukant, C. Wallmann, M. Müller, M. Korte, B. Stirn, H.G. Haldenwanger and U. Glatzel, Fluxless laser beam joining of aluminum with zinc coated steel: Science and Technology of Welding and Joining, 10-2 (2005), 219-226.

4) T. Sakiyama, G. Murayama, Y. Naito, K. Saita, Y. Miyazaki, H. Oikawa and T. Nose, Dissimilar Metal Joining Technologies for Steel Sheet and Aluminum Alloy Sheet in Auto Body: Nippon Steel Technical Report, 103 (2013), 91-98.

5) C. Dharmendra, K. P. Rao, J. Wilden and S. Reich, Study on laser welding-brazing of zinc coated steel to aluminum alloy with a zinc based filler: Materials Science and Engineering A, 528 (2011), 1497-1503.

6) K. Saida, W. Song and K. Nishimoto, Diode laser brazing of aluminum alloy to steels with aluminum filler metal, Science and Technology of Welding and Joining, 10-2 (2005), 227-235.

7) R. Cao, J. H. Sun, J. H. Chen and P. Wang, Weldability of CMT Joining of AA6061-T6 to Boron Steels with Various Coatings, Welding Journal, 93 (2014), 193-204.

8) J. Lin, N. Ma, Y. Lei and H. Murakawa, Shear strength of CMT brazed lap joints between aluminum and zinc-coated steel, Journal of Materials Processing Technology, 213 (2013), 1303-1310. 